\title{
Origen y desarrollo de la inspección en El Salvador
}

Leyes básicas que dan origen a la inspección de trabajo entre 1911 y 1950.

Ley sobre accidentes de trabajo de 1911 y la creación del despacho de trabajo:

La Ley sobre Accidentes de Trabajo del once de Mayo de 1911, constituyó el primer y más claro antecedente de la potestad del Estado de ejercer actos relativos a la inspección de trabajo en El Salvador, como medio para tutelar los derechos y garantías de los trabajadores de aquella época. En términos generales, este cuerpo normativo establecía incipientes conceptos jurídicos, competencias, procedimientos y sanciones para que los trabajadores pudieran reclamar al patrono en casos de accidentes de trabajo ${ }^{1}$.

Esta ley se establecía que el patrono era responsable de los accidentes de trabajo ocurridos a sus operarios, con motivo y en ejercicio de la profesión o trabajo que realizaran, a menos que el accidente se debiera a fuerza mayor o caso fortuito, extraño al trabajo en que se produjera el acciden-

1 La Ley sobre Accidentes de Trabajo, fue Decretada por la Asamblea Nacional Legislativa el 11 de mayo de 1911. Publicada en el Diario Oficial del 13 de mayo de 1911. Recopilación de Leyes y Reglamentos sobre Trabajo y Seguridad Social. Marzo de 1954. Pág. 357 y sig. te, o que este se a hubiere verificado por notable descuido o grave imprudencia del operario.

Este cuerpo normativo otorgaba competencia al Alcalde de la población y en su defecto, a cualquiera de los Jueces de Paz de la localidad, para que se constituyeran al lugar en que había ocurrido el accidente a practicar una inspección "lo más minuciosa posible", para establecer las circunstancias, causas y efectos del acontecimiento, lo cual asentaría en acta. La ley regulaba que en estos casos, se debía practicar un reconocimiento en la victima, por medio de dos profesores de cirugía y en su defecto, por medio de dos prácticos los cuales declararían sobre la naturaleza del daño y de sus probables consecuencias. Los Jueces de Primera Instancia de lo Civil, eran los funcionarios competentes para conocer de las demandas sobre reclamaciones de indemnizaciones por accidentes de trabajo.

El segundo antecedente de la inspección de trabajo, tiene lugar en 1927 con la creación del Despacho de Trabajo, dependencia del Ministerio de Gobernación, cuya finalidad era vigilar el cumplimiento de las normas laborales en los talleres y demás centros de trabajo. En el mismo año y a solo tres meses de la creación del despacho, se constituyeron 
las Juntas de Conciliación integradas por cuatro miembros titulares y dos suplentes, cuyas atribuciones eran, velar por que se cumplieran las leyes y reglamentos en materia de trabajo, para lo cual tenían la facultad de ingresar a los centros de trabajo. Estos antecedentes son considerados como las piedras que le dan el cimiento a la construcción del sistema de inspección de trabajo en El Salvador.

Ley de Protección a Empleados de Comercio:

En mayo de 1927 el Poder Legislativo decreta la Ley de Protección a los Empleados de Comercio, la cual contenía normas que regulaban la obligatoriedad del patrono a llevar un libro en el que debía inscribir a todo trabajador a su servicio, haciendo constar la clase de ocupación, el día de inicio de la relación laboral, el plazo del contrato, las horas de trabajo y "el precio" que devengaría del trabajador ya sea diario, semanal o mensual ${ }^{2}$.

De este asiento el patrono debía expedir una constancia al trabajador, la cual de acuerdo al artículo uno de esta ley, se utilizaría para que el trabajador la presentara a la Junta de Conciliación respectiva, y fuera tomada razón de ella en un libro especial, sin perjuicio de la obligación que tenía el patrono de remitir a la Junta de Conciliación en los meses de enero y julio de cada año la lista de los empleados que tuviere con distinción de salvadoreños y extranjeros.

La creación de las Juntas de Conciliación, también constituye otro de los antecedentes de la inspección de trabajo, quienes de acuerdo a la ley en comento, tenían facultad para imponer multas de diez a veinticinco colones por cada infracción a la ley que cometiera el patrono.

En este cuerpo normativo se regulaban aspectos que para esa época constituían avances sin precedentes en materia de protección laboral, nos referimos a regulaciones como: Remuneración de horas extraordinarias, jornada laboral de ocho horas diarias, vacaciones remuneradas, jornada de trabajo diferenciada para mujeres y menores de quince

2 La Ley de Protección a los Empleados de Comercio, fue publicada en el Diario oficial del 17 de Junio de 1927. Y su vigencia derogó, la Ley de Protección a los Empleados de Comercio de fecha 29 de mayo de 1926. Fuente: Recopilación de Leyes y Reglamentos sobre Trabajo y Seguridad Social. Marzo de 1954. Pág. 257 y sig. años y el dato más relevante a los fines de nuestro análisis, es que en caso de terminación de la relación laboral se regulaba el pre aviso de la forma siguiente: Art. 8 inciso último: "El patrono comunicará a la Junta y al empleado, por escrito, el día en que haya hecho saber a éste que habrá de cesar en la ocupación. La Junta por medio de un inspector 0 en otra forma fehaciente, averiguará si es verdad que se ha hecho el desahucio y el resultado lo hará constar la Junta en un libro que llevará al efecto, para que sirva de prueba".

Ley de Botiquines de 1935:

En 1935 bajo la dictadura del General Maximiliano Hernández Martínez, se decreta la Ley de Botiquines, cuyo objetivo era que los patronos proporcionaran medicinas a las personas que trabajaban en el campo y en los talleres de la ciudad que carecían de los medios necesarios para combatir enfermedades de manera oportuna y en casos de urgencia. Esta ley aplicaba a los patronos que tuvieran más de diez personas trabajando bajo su dependencia, debiendo tener en el lugar más apropiado, por su cuenta y para otorgar gratuitamente medicamentos básicos ${ }^{3}$.

La Ley de Botiquines establecía además que el patrono que dentro de dos meses de publicada la presente ley no hubiere cumplido con las disposiciones establecidas, incurría en una multa de veinte colones mensuales, hasta que le diera cumplimiento. Esta multa era cobrada gubernativamente por el Alcalde respectivo y en beneficio del hospital de la jurisdicción o del más próximo. El dato más importante a Ios fines de nuestra reflexión era que la Ley facultaba expresamente a los Ministerios de Gobernación y de Trabajo, Beneficencia y Sanidad, para que dictaran todas las disposiciones necesarias para la efectividad de dicha ley.

Al analizar en su contexto la Ley de Protección de Empleados de Comercio y la Ley de Botiquines podemos afirmar, que en su génesis la inspección de trabajo fue realizada por

3 La Ley de Botiquines de 1935 estaba redacta en tres artículos y detallaba el tipo de medicamentos que debían tener los patronos, entre las cuales mencionaba: Píldoras de Sulfato, de antipirina, bicarbonato de soda, sal de glover, tabletas de permanganato de potasa, tintura de yodo, alcohol, algodón, gasa, vendas y otras. Esta Ley entró en vigencia mediante Decreto Legislativo No 25 del 20 de Julio de 1935, publicado en el Diario No 165 Tomo 119 de fecha 25 de julio del mismo año.- 
autoridades de elección popular territorial como los alcaldes, autoridades jurisdiccionales como Jueces de primera instancia y de paz, y también por autoridades que ahora se conocen como funcionarios de elección de segundo grado, como fueron los Ministros de Gobernación y de Trabajo. La otra conclusión que podemos obtener es que para 1935 al menos había una ley destinada a los trabajadores del comercio, es decir de la ciudad, y otra ley tendente a beneficiar a los trabajadores agrícolas y de talleres, con lo cual quedaba mínima e incipientemente cubiertas las principales áreas del mercado laboral de aquella época. Por supuesto no podemos obviar en el análisis que el Presidente Martínez tenía un problema socio laboral agudo, pues había reprimido a campesinos organizados y mantenía un estado basado en la fuerza de las armas, y estas leyes le darían un respiro ante la opinión pública nacional e internacional.

\section{La Constitución Política de 1939:}

El 20 de enero de 1939 y bajo la dictadura del Gral. Maximiliano Hernández Martínez, la Asamblea Nacional Constituyente decreta una Constitución que por primera vez dedicaba un capitulo a la Familia y Trabajo, del cual resaltaba el contenido del Art. 62 que decía: “El trabajo gozará de la protección del Estado por medio de leyes que garanticen la equidad y la justicia en las relaciones entre patronos y empleados u obreros. El trabajo de las mujeres y de los menores de dieciocho años deberá ser especialmente reglamentado..."

Esta constitución también reguló que los conflictos que surgieran entre el capital y el trabajo o entre patronos y empleados u obreros, serían resueltos por un tribunal de arbitraje o de conciliación, que una ley especial determinaría. Con tales disposiciones se estaban estableciendo las bases de un orden procesal que permitiría resolver los conflictos laborales.

4 La Constitución Política de la República de El Salvador, de 1939 fue decretada por la Asamblea Nacional Constituyente el 20 de enero de 1939. Fuente: Las Constituciones de la República de El Salvador 1824- 1962. Primera Parte. Primera Edición 1993. Publicación de la Unidad Técnica Ejecutora. UTE. San Salvador. El Salvador. Pág. 233 y siguientes.

\section{Creación del Ministerio de Trabajo y Previsión Social:}

Uno de los avances más significativos en la historia institucional de El Salvador, ocurre en enero de 1946, con la creación del Ministerio de Trabajo y Previsión Social y del Departamento Nacional del Trabajo dependiente del citado ministerio ${ }^{5}$. Este importante avance se logra en un contexto político que favoreció los cambios sociales, debido a que recientemente había terminado la dictadura del Gral. Martínez producto de un golpe de Estado, esta situación llevó a la creación de una nueva constitución política en 1945, la cual no solo regulaba un capitulo sobre la Familia y el Trabajo como en la Constitución Política de 1939, sino que elevó a rango constitucional derechos y garantías tales como: La protección del salario y la creación de un sistema de fijación de salario mínimo, principio de igualdad de remuneración, establecimiento de una jornada máxima de trabajo, establecimiento de un día de descanso remunerado por cada semana de trabajo, "derecho del trabajador para que se señalen las condiciones que debían reunir los locales de trabajo y las seguridades que debían adoptarse para su vida y su salud" ${ }^{\prime 6}$; así como, el derecho de los trabajadores a la huelga y el de los patronos al paro.

En este contexto nace el Departamento Nacional de Trabajo, que de acuerdo a los considerandos del decreto de creación, tiene tres propósitos: a saber: 1) "Reglamentar en debida forma las relaciones entre el capital y el trabajo a efecto de determinar sus derechos y obligaciones recíprocos, y asegurarles un desenvolvimiento armónico; 2) Que es necesario recopilar datos y elementos de información y realizar los estudios que requiera la preparación de las leyes sobre el capital y el trabajo; y 3) Que los problemas del capital y el trabajo ameritan una pronta solución ${ }^{7 . "}$

5 Decreto de la Asamblea Nacional Legislativa № 134 de fecha 14 de octubre de 1946, publicado en Diario Oficial del 22 de octubre del mismo año.- Recopilación de Leyes y Reglamentos sobre Trabajo y Seguridad Social. Marzo 1954. Pág 21 y sig.

6 La Constitución Política de la República de El Salvador de 1945, fue puesta en vigencia mediante el Decreto Legislativo № 251 del fecha 29 de noviembre del mismo año, el cual en su artículo uno decía: "Tiénese como Constitución Política de la República, la decretada el 13 de agosto de 1886 con las siguientes enmiendas..." Fuente: Las Constituciones de la República de El Salvador 1824- 1962. Primera Parte. Primera Edición 1993. Publicación de la Unidad Técnica Ejecutora. UTE. San Salvador. El Salvador. Pág. 315 y siguientes.

7 Ley de Creación del Departamento Nacional de Trabajo, fue puesto en vigencia mediante el Decreto Legislativo № 321, Publicado en 
El Departamento Nacional de Trabajo, estaba cargo de un Primer y Segundo Director designados por el Poder Ejecutivo, dentro de sus atribuciones se mencionaba la de "Super vigilar el cumplimiento de las leyes de trabajo", para lo cual la misma ley regula la existencia y conformación de dos instancias claves para la solución de los conflictos laborales, de una parte Las Juntas de Conciliación, y de otra, El Consejo del Trabajo; las primeras era presididas por el Delegado Inspector Departamental de Trabajo e integrada además, en caso de conflicto, con un representante por cada una de las partes.

En esta ley se le asignó un rol protagónico al Delegado Inspector, en se regulaba que en cuanto tenga conocimiento de un conflicto entre capital y trabajo, el Delegado Inspector Departamental daría aviso al segundo Director del Departamento Nacional del Trabajo, para que este procediera a integrar la Junta de Conciliación respectiva, convocando a las partes para una audiencia en la que procuraría avenirlas, proponiendo la solución que estimara justa y equitativa.

La ley en comento también reguló algunos preceptos que todavía se mantienen en la legislación secundaria, ahora aplicados por otras autoridades, por ejemplo: Los fallos pronunciados en los conflictos de trabajo debían hacerse cumplir por la Junta de Conciliación en forma gubernativa; en cualquier estado del conflicto las partes podían darlo por terminado mediante conciliación y arbitraje; tanto trabajadores como patronos podían acudir ante el Director del Departamento Nacional de Trabajo a solicitar su intervención; Obligatoriedad de suministrar datos o informes que solicitara el Departamento a las empresas, por último, y por ello no menos importante, la competencia que la ley le daba al Departamento y a los Delegados Inspectores Departamentales, incluía la intervención en los conflictos que pudieran suscitarse entre patronos y empleados del comercio, como entre patronos y trabajadores del campo.

Un dato importante es que esta ley derogó la conformación de las Juntas de Conciliación que venían funcionando desde junio de 1927, e instauró un nuevo andamiaje institucional

el Diario Oficial del 15 de enero de 1946. Recopilación de Leyes y Reglamentos sobre Trabajo y Seguridad Social. Marzo de 1954. Pág. 27 y sig. en el que encontraban las nuevas Juntas de Conciliación presididas como ya se dijo por el Delegado Inspector de Trabajo, El Consejo del Trabajo, Consejo Nacional del Trabajo y el Ministerio de Trabajo; esta era la jerarquía que debían seguir los recursos que se planteaban en los conflictos de trabajo.

Ley Especial de Procedimientos para Conflictos Individuales de Trabajo:

En 1949 bajo la administración de un Consejo Revolucionario de Gobierno, se decreta la Ley de Especial de Procedimientos para Conflictos Individuales de Trabajo, cuya principal característica, fue dar un rol jurisdiccional a los Delegados Inspectores de Trabajo, similar a las facultades que ahora poseen los Jueces de lo Laboral o con jurisdicción en dicha materia.

Mediante este cuerpo normativo, los Inspectores de trabajo conocían en primera instancia los reclamos de trabajadores contra sus patronos y de éstos contra aquellos, que pudieran suscitase conforme a las leyes de trabajo de esa época. La competencia que ejercían era departamental y dentro del proceso calificaban los requisitos que debía contener la demanda, citaban a las partes a la conciliación, pero para la validez del resultado de la conciliación, necesitaban la aprobación del Director General del Departamento Nacional de Trabajo, excepto en las conciliaciones que tenían lugar en el Departamento de San Salvador.

Si la conciliación no procedía por haberse violado derechos irrenunciables del trabajador, o si no comparecía el demandado a la audiencia, los inspectores procedían al emplazamiento del demandado para que contestara la demanda, y en el caso de no hacerlo en el término señalado, se tenía por contestada la demanda en sentido negativo y se proseguía en rebeldía; luego se ordenaba la apertura a pruebas y vencido dicho término, los Delegados Inspectores pronunciaban sentencia definitiva, para lo cual el Art. 18 de la ley en mención les imponía que observaran las formalidades prescritas para las sentencia reguladas en el Código de Procedimientos Civiles.

60 
Esta ley regulaba una estructura básica del proceso laboral muy parecida al actual juicio ordinario de trabajo, incluyendo los recursos que podían interponerse de las resoluciones y los medios de prueba que en la actualidad regula el Código de Trabajo.

De esta ley también llama la atención, algunos aspectos que en la actualidad se encuentran regulados incluso con la misma redacción que el actual Código de Trabajo, como son: el procedimiento de la audiencia conciliatoria, las presunciones que operan a favor de trabajador y las reglas de la prueba instrumental. Con lo cual podemos afirmar que esta ley es uno de los antecedentes del cual se nutre el actual Código de Trabajo.

A los efectos del presente trabajo, es importante destacar que esta ley le dio un estatus diferente al Delegado Inspector, ya que en la Ley de Creación del Departamento Nacional de Trabajo, venia de ser integrante de las Juntas de Conciliación que únicamente procuraba avenir a las partes en conflicto, en tanto que en esta ley, se convertía en un juzgador unipersonal de primera instancia de resolución de dichos conflictos, por supuesto tenía ciertas limitantes como la ya mencionada en cuanto a la validación del arreglo conciliatorio cuando no ejercía sus funciones en el Departamento de San Salvador ${ }^{8}$.

B. Constitucionalización del sistema de inspección de trabajo. La Constitución de 1950:

La constitucionalización de los derechos y garantías básicas de los trabajadores alcanza su máximo expresión, con la vigencia de la Constitución Política de 1950, que introduce una nueva filosofía política producto del esplendor del Estado social de derecho y su intervención como subsidiario y responsable de las necesidades básicas del ser humano. Es en este contexto en que por primera vez se ubica con rango constitucional a la inspección de trabajo en El Salvador, por lo cual es menester transcribir lo que a su letra expresa

8 La Ley Especial de Procedimientos para Conflictos Individuales de Trabajo, fue creada mediante Decreto № 330 del Consejo Revolucionario de Gobierno. Publicado en el Diario oficial del 30 de septiembre de 1949. Recopilación de Leyes y Reglamentos sobre Trabajo y Seguridad Social. Marzo de 1954. Pág. 331 y sig. el inciso segundo del Art. 195 de aquel texto: "El Estado mantendrá un servicio de inspección técnica encargado de velar por el fiel cumplimiento de las normas legales de trabajo, asistencia, previsión y seguridad social, de comprobar sus resultados y de sugerir las reformas pertinentes ${ }^{9 "}$.

\section{Ley de Inspección General de Trabajo:}

Inserto en aquel ambiente que en el campeaban los principios del Estado Social de Derecho, y a solo tres días para que entrara en vigencia la constitución de 1950, el Consejo de Gobierno Revolucionario, decreta la Ley de Inspección General de Trabajo, cuyas motivaciones de acuerdo a su texto, fueron: "I. Que es de primordial interés para el Estado el debido cumplimiento de las leyes de trabajo, tanto de parte de trabajadores como de patronos. y II. Que es necesario investir a la Sección de Delegación y Vigilancia del Departamento Nacional de Trabajo, de las facultades suficientes para su mejor funcionamiento ${ }^{10}$."

Esta Ley de Inspección de Trabajo conformada por dieciocho artículos regulaba los aspectos siguientes:

1. La conformación de un cuerpo de inspectores que velara por el cumplimiento y respeto de las leyes de trabajo;

2. Vigilancia hacía los patronos, a fin de que estos llevaran un control sobre ingreso y retiro de trabajadores, pago de horas extras, descansos, vacaciones, asistencia médica y demás prestaciones establecidas a favor de los trabajadores;

3. Visita a los lugares de trabajo;

4. Facultades de los inspectores en cuanto a la investigación y comprobación de la observancia de las disposiciones legales de trabajo y previsión social;

9 Constitución Política de El Salvador de 1950. Decreto № 14 de la Asamblea Nacional Constituyente. Por disposición del Artículo 226 del mismo texto, ésta constitución entró en vigor el 14 de septiembre de 1950.- Fuente: Las Constituciones de la República de El Salvador 1824- 1962. Primera Parte. Primera Edición 1993. Publicación de la Unidad Técnica Ejecutora. UTE. San Salvador. El Salvador. Pág. 359 y siguientes.

10 La Ley de Inspección General de Trabajo, fue creada mediante Decreto № 816 del Consejo Revolucionario de Gobierno de la República de El Salvador, el 11 de septiembre de 1950, publicado en el Diario Oficial de la misma fecha. 
5. Inspección sobre condiciones de seguridad de los trabajadores, a fin de prevenir accidentes de trabajo;

6. Verificación de avisos obligatorios que el patrono debía informar a la Sección de Delegación y Vigilancia, tales como: aviso de ingreso y retiro de trabajadores, aumentos o disminución de sueldos, cambios de cargo de los trabajadores y descansos por vacaciones;

7. Obligación de los patronos de suministrar datos que le fueren solicitados;

8. Facultad de los inspectores para aconsejar a los patronos y trabajadores de la adopción de medidas para evitar posibles conflictos asentadas en actas la relación de los hechos y las medidas que hubiere sugerido; lo cual tenía como ulterior propósito prevenir conflictos;

1. Dar aviso a las autoridades sanitarias para la práctica y verificación de condiciones higiénicas en los centros de trabajo;

2. Regulación de un régimen de infracciones y multas;

3. Dar aviso al Director del departamento para que éste procediera al cierre provisional de lugares de trabajo en casos de extrema gravedad.

4. Establecía la prohibición para que los patronos no tomaran represalias contra sus trabajadores por denuncias formuladas a las autoridades competentes:

5. Regulación de un procedimiento para la imposición de multas; $y$

6. Prohibiciones a los inspectores bajo pena de ser suspendidos hasta por un mes sin goce de sueldo o la destitución del cargo según la gravedad por las causas siguientes:

a) Divulgar datos que obtuvieran con motivo del desempeño de sus funciones;

b) Asentar hechos falsos en las actas 0 informes que levantaren;

c) Aceptar dádivas de los patronos o de los trabajadores; 0

d) Por extralimitarse en el desempeño de sus funciones.
Si comparamos el contenido de esta ley con las actuales disposiciones de la Ley de Organización y Funciones del Sector Trabajo y Previsión Social, LOFSTPS, en cuanto a las facultades de los inspectores de trabajo, nos damos cuenta que es exactamente el mismo marco jurídico de actuación, y que legislativamente muy poco se ha avanzado en esta materia.

Ley de Sindicatos y Ley de Riesgos Profesionales: Atribuciones jurisdiccionales de los inspectores de trabajo:

En 1951 se decreta una nueva Ley de Sindicatos de Trabajadores $^{11}$, que deroga la que había sido aprobada apenas el año anterior, en ella se consignaba: "Los sindicatos que en el desarrollo de sus actividades infrinjan las disposiciones de la presente ley, incurrirán en las penas de multa, suspensión o disolución, según los casos." Las sanciones señaladas eran impuestas mediante un procedimiento por escrito seguido ante el Delegado Inspector Departamental del domicilio del sindicato, quién mandaba a oír al sindicato demandado para que manifestara su defensa y una vez concluido el término probatorio pronunciaba sentencia.

El Delegado Inspector también tenía competencia para multar al patrono que perturbara el ejercicio de los derechos sindicales o que despidiera a trabajadores con el objetivo de hacer desaparecer el sindicato, a tal punto que de acuerdo a la ley, no se podía declarar la disolución de un sindicato de empresa por insuficiencia del número de afiliados, cuando esta insuficiencia sobreviniera a consecuencia de despidos o desmejoramientos injustificados.

En 1956 bajo la presidencia del Coronel Oscar Osorio, la Asamblea Legislativa decretó dos leyes importantes en materia de protección de los trabajadores, en las que se reafirmaba el rol protagónico a los Inspectores de Trabajo, una de ellas fue la Ley de Riegos Profesionales ${ }^{12}$, que se

11 La Ley de Sindicatos de Trabajadores fue creada por Decreto Legislativo № 353. Aprobada por la Asamblea Legislativa el 13 de agosto de 1951. Esta Ley derogó todas las disposiciones legales dictadas en materia sindical, fundamentalmente la Ley de sindicatos Promulgada el 9 de agosto de 1950 por el Consejo Revolucionario de Gobierno. Recopilación de Leyes y Reglamentos sobre Trabajo y Seguridad Social. El Salvador. Pág. 57

12 La Ley de Riesgos Profesionales, fue creada mediante Decreto Legislativo $N^{\circ} 2118$. Publicada en el Diario Oficial del 20 de junio de 
aplicaba a los trabajadores al servicio de patronos privados, del Estado, de los Municipios y de las Instituciones Oficiales Autónomas, excluyendo a los trabajadores del servicio doméstico, a los trabajadores a domicilio y a los trabajadores que prestaban servicios a personas naturales que por su propia naturaleza no les reportaran lucro, o en labores eventuales que no debieran durar más de una semana, ni requerían el empleo de más de cinco personas.

Esta ley otorgaba competencia al Jefe de Sección y al Director de Departamento de Inspección de Trabajo, para aplicar la Ley de Inspección General de Trabajo, en caso de infracciones, así como también expresaba, que mientras se creaban las judicaturas de trabajo los Delegados Inspectores Departamentales de Trabajo, harían las veces de los jueces de trabajo.

La vigencia de esta ley derogó la Ley sobre Accidentes de Trabajo del 11 de mayo de 1911, que a nuestro entender fue el primer cuerpo normativo, completo y sistemáticamente diseñado para proteger al trabajador de los riegos laborales.

\section{Ley sobre Seguridad e Higiene en los Centros de Trabajo:}

El otro cuerpo normativo que se decretó bajo la presidencia del Coronel Osorio, fue la Ley sobre Seguridad e Higiene en los Centros de Trabajo $^{13}$, desde esa época a nuestros días vigente, cuya finalidad se justifica a partir de la necesidad de adoptar medidas tendientes a proteger la vida, la integridad corporal, y la salud de los trabajadores, así como la creación de un organismo consultivo en que estuvieran representados el Estado, los patronos y los trabajadores.

Esta ley fue creada para regular las condiciones de seguridad e higiene en que debían ejecutar las labores los trabajadores al servicio de patronos privados, del Estado, los Municipios y las Instituciones Oficiales Autónomas.

1956. Recopilación de Leyes y Reglamentos sobre Trabajo y Seguridad Social. El Salvador. Pág. 423 y sig. Recopilación de Leyes y Reglamentos sobre Trabajo y Seguridad Social. El Salvador. Pág. 35

13 La Ley sobre Seguridad e Higiene del Trabajo, fue creada mediante Decreto Legislativo № 2117. Publicada en el Diario Oficial del 13 de junio de 1956. Recopilación de Leyes y Reglamentos sobre Trabajo y Seguridad Social. El Salvador. Pág. 461
Con motivo de esta ley los patronos debían adoptar y poner en práctica medidas adecuadas de seguridad e higiene en los centros de trabajo, tales como: suministro, uso y mantenimiento de los equipos de protección personal, edificaciones e instalaciones en condiciones ambientales adecuadas e implementación de medidas adecuadas en cuanto a las operaciones y procesos de trabajo. Esta normativa no solo obligaba a patronos sino también a trabajadores, en tanto debían cumplir las normas sobre seguridad e higiene reguladas en la ley.

Uno de los aportes más importantes de la Ley sobre Seguridad e Higiene en los Centros de Trabajo, es promover la creación de los comités de seguridad en los centros de trabajo industriales de más de veinte trabajadores, los cuales se integrarán por igual número de representantes de los obreros y de los patronos; y la creación de la Comisión de Seguridad e Higiene del Trabajo, como un órgano consultivo dependiente del Ministerio de Trabajo y Previsión Social, constituida por un representante del Instituto Salvadoreño del Seguro Social, un representante del Ministerio de Salud Pública y Asistencia Social, dos representantes patronales elegidos por las asociaciones de patronos más representativas, dos representantes de los trabajadores elegidos por Ios sindicatos de trabajadores y un representante del Ministerio de Trabajo.

Con la composición de este organismo quedaba establecida en forma expresa la importancia del tripartismo, y la necesidad de la búsqueda de consensos en temas de tanta relevancia como fue y sigue siendo la seguridad e higiene en los centros de trabajo.

Otro de los aportes de la ley a la consolidación de la institucionalidad en materia de trabajo, y concretamente de la inspección, fue la competencia que les otorgó a los inspectores de trabajo, ya que expresamente el Art. 21 regula: "Los Inspectores de trabajo serán los funcionarios encargados de velar por el cumplimiento y respeto a las disposiciones de esta ley y de sus reglamentos, así como de las recomendaciones técnicas particulares que se dicten por el Departamento Nacional de previsión Social". 
Estas competencias incluyen la imposición de sanciones por infracciones a la ley cometidas por patronos, incluso la clausura de locales o el retiro de maquinarias, artefactos, aparatos, equipos u objetos peligrosos que pudieran dañar o poner en peligro la vida o la integridad corporal de los trabajadores en los centros de trabajo. Estas medidas eran tomadas por el Director del Departamento de Inspección de Trabajo. El citado funcionario también tenía facultades para autorizar la reanudación o apertura de los locales cuando hubieren superado o desaparecido las causas que motivaron el cierre o clausura.

\section{La Constitución Política de 1962:}

En 1962 se dicta una nueva Constitución Política ${ }^{14}$, bajo la administración de un Directorio Cívico Militar, en la que básicamente se mantienen los preceptos de la constitución de 1950, con un agregado importante en materia de trabajo: Se reconoce el derecho de los empleados y obreros de las Instituciones Oficiales Autónomas y Semi Autónomas, sin distinción de nacionalidad, sexo, raza, credo o ideas políticas, a asociarse libremente para la defensa de sus respectivos intereses, formando asociaciones profesionales 0 sindicatos.

Esta Constitución mantiene inmutable el establecimiento de un servicio de inspección técnica de trabajo, tal como lo reguló la anterior carta magna, pero en sus disposiciones transitorias regulaba lo siguiente: "Art. 224.- El Código de Trabajo a que se refiere el artículo 182 de esta Constitución, deberá promulgarse dentro del plazo de un año a contar de la vigencia de esta constitución. Mientras tanto continuarán en vigencia las leyes laborales que actualmente rigen y podrá regularse por leyes especiales la materia que contiene al Capitulo II, Título XI de esta Constitución". Este precepto constitucional implicaba que la constitución consideraba la existencia de un Código de Trabajo, pero aún no había sido decretado, por lo cual a esta fecha todavía existía una dispersión de leyes laborales, que pretendía ser integrada en un solo cuerpo normativo.

14 La Constitución Política de 1962, fue Decretada por la Asamblea Constituyente, mediante Decreto № 6 de fecha 8 de enero del mismo año. Fuente: Las Constituciones de la República de El Salvador 1824- 1962. Primera Parte. Primera Edición 1993. Publicación de la Unidad Técnica Ejecutora. UTE. San Salvador. El Salvador. Pág. 419
Ley Orgánica del Ministerio de Trabajo y Previsión Social:

En 1963 se decreta la Ley Orgánica del Ministerio de Trabajo y Previsión Social, integrado por una Oficialía Mayor y cuatro Departamentos, uno ellos era el de Inspección de Trabajo, el que a su vez estaba constituido por dos secciones: a) La de industria y comercio; y b) la de inspección agrícola. El Director del Departamento tenía atribuciones para ordenar las investigaciones que fueran necesarias en los establecimientos y centros de trabajo, relativas al cumplimiento del Código de Trabajo y a iniciativa propia o por requerimiento de alguna autoridad o persona interesada. Así como también conocía en apelación de las resoluciones pronunciadas por los Jefes de Sección.

Si bien es cierto esta ley sistematizó de mejor forma la estructura del Ministerio de Trabajo, también es de hacer notar que en materia de inspección no introdujo ninguna nueva atribución o delegación, más bien ordenó lo que ya existía.

El mayor avance que se logró mediante este cuerpo normativo, fue separar las tareas y funciones del Departamento de Inspección de Trabajo de las encomendadas al Departamento Nacional de Previsión Social, a este último correspondía "Promover en los lugares de trabajo la adopción de medidas de seguridad e higiene que protegieran la vida, la salud, la integridad física y la capacidad de trabajo del personal, así como dictar recomendaciones técnicas con el fin de mejorar las condiciones de trabajo y de eliminar los riesgos de accidentes y enfermedades en los lugares de trabajo.

Esta ley regulaba que para proceder a clausurar un local de trabajo o algunas de sus dependencias, el Departamento Nacional de Previsión Social, debía pedir al Director del Departamento de Inspección que autorizara dicha clausura, pues la competencia para efectos sancionatorios la poseía este último, tal como aún se mantiene en la actualidad ${ }^{15}$.

15 Ley Orgánica del Ministerio de Trabajo y Previsión Social. Decretada por la Asamblea Legislativa, mediante Decreto № 455, de fecha 27 de noviembre de 1963, publicada en el Diario Oficial № 232, Tomo № 201, del 10 de diciembre de 1963.- Recopilación de Leyes Laborales. Editorial Jurídica Salvadoreña. El salvador 1991. pág. 207 


\section{La Constitución de 1983:}

La última constitución decretada y vigente a la fecha es la de $1983^{16}$, en la que se mantiene el mismo espíritu y letra de la constitución de 1950 y de 1962, con algunos cambios que no son tan sustanciales como fueron los introducidos en la Constitución de 1950. No obstante hay que resaltar que la actual carta magna, regula un catalogo de derechos, garantías y principios que reflejan el avance que en esta materia ha experimentado El Salvador, los cuales se traducen en una plataforma básica en cuanto a contratación individual de trabajo, condiciones mínimas de seguridad para la ejecución de las labores en los centros de trabajo, mención de derechos de la mujer trabajadora en su ámbito reproductivo o de procreación, normas sobre seguridad social, establecimiento de la jurisdicción especial de trabajo, libertad sindical para trabajadores y empleados privados y de las instituciones oficiales autónomas, y garantía de estabilidad para los trabajadores miembros de juntas directivas sindicales, entre otros.

C. Antecedentes históricos de la inspección de trabajo en mundo:

Las normas mínimas del derecho laboral nacen a inicios del siglo XX producto de relaciones de trabajo caracterizadas por la sobre explotación de hombres, mujeres y niños que trabajaban largas jornadas en condiciones infrahumanas sin una retribución digna y sin ningún tipo de esperanza de mejorar sus condiciones de vida. En este panorama el Estado decide intervenir, por un lado creando normas jurídicas para minimizar el impacto de los problemas sociales que la sobreexplotación había creado, y por otro lado, creando de forma paralela una inspección que garantizara el eficaz cumplimiento de esas normas.

En este escenario se gestan antecedentes importantes en el desarrollo de las relaciones laborales dignas y de los procesos de inspección de trabajo: En 1802 en Gran Bretaña existió "una inspección facultativa destinada a impedir que

16 La Constitución de la República de El Salvador, fue decretada por la Asamblea Legislativa mediante Decreto $N^{\circ} 38$, de fecha 15 de diciembre de 1983, y entró en vigencia en 29 del mismo mes y año.- las condiciones higiénicas de los locales favorecieran el desarrollo de enfermedades contagiosas ${ }^{17 " . ~ E n ~} 1839$ una ley de Prusia estableció la inspección facultativa confiada a una comisión mixta de la policía y de los inspectores escolares. Fue en 1853 que se crea la inspección obligatoria, orientada únicamente a la protección de los menores; y en 1869 se extendió la inspección obligatoria a todas las actividades laborales mediante una ley de Bismarck.

Señala Suárez González que el primer intento por crear un cuerpo especial de funcionarios encargados de asegurar la aplicación de las leyes sociales, (entiéndase leyes laborales) fue en Francia, mediante una ley promovida el 19 de mayo de 1874 , en la que se comprendía un grupo de quince inspectores nombrados por el Estado pero retribuidos tanto por este último, como por los Consejos Generales, por lo cual la moción no llegó a un feliz desempeño, pues Ios Consejos argumentaban que esta era una obligación del Estado.

No fue sino hasta el 2 de noviembre de 1892 donde se crea una ley para que la inspección de trabajo adquiriera verdaderamente una estructura de cuerpo administrativo del Estado con miembros reclutados por concurso y dotados de un estatuto ${ }^{18}$.

Como un refuerzo a la ley anterior en 1898 el parlamento Francés decide expedir la Ley de Accidentes de Trabajo ${ }^{19}$, que introduce la Teoría del Riesgo Profesional. Con estos hechos se va desencadenando una serie de acontecimientos históricos que enriquecen la inspección de trabajo, tal como fue La Declaración de Derechos Sociales de la Constitución Mexicana de 1917, La Constitución Alemana de Weimar de 1919, que reconocen derechos fundamentales en los trabajadores.

17 Instituciones de Derecho del Trabajo y de la Seguridad Social. Coordinador: Néstor del Buen Lozano y otros. Artículo elaborado por Fernando Suárez González. Capitulo 42. Primera Edición. Universidad Autónoma de México. 1997 pág. 783.

18 Instituciones de Derecho del Trabajo y de la Seguridad Social. Coordinador: Néstor del Buen Lozano y otros. Artículo elaborado por Fernando Suárez González. Capitulo 42. Primera Edición. Universidad Autónoma de México. 1997 pág. 784.

19 De la Cueva Mario. "El Nuevo Derecho Mexicano del Trabajo" Décimo Quinta Edición. Tomo I .Editorial Porrúa. 1998. Pág.19. 
Fue así como la organización de la inspección de trabajo fue adquiriendo relevancia en Europa y se volvió objeto de estudios y propuestas para establecer una homologación mínima entre países, muestra de ello es que el tema fue abordado en las conferencias internacionales de Berlín en 1890, en los congresos internacionales en Zurich en 1897, París en 1900 y Berna en 1905. Estos antecedentes coadyuvaron a la concreción de la parte XIII del Tratado Versalles por el cual se crea la Organización Internacional del Trabajo, en 1919, que en sus principios generales considera que: "Todos los Estados habrán de organizar un servicio de Inspección del Trabajo para asegurar la aplicación de las leyes y reglamentos relativos a la protección de los trabajadores; este servicio habrá de incluir a mujeres ${ }^{20}$ " Con este Antecedente se da un salto cualitativo hacia la construcción de los sistemas de inspección del trabajo en mundo, consagrado desde la misma Constitución de la OIT en 1919, que en su Art. 10.2 literal b) en síntesis establece: Que la Oficina Internacional del Trabajo, prestará a los gobiernos cuando éstos lo soliciten, toda la ayuda posible para elaborar una legislación basada en las decisiones de la conferencia y para mejorar las prácticas administrativas y los sistemas de inspección.

En este mismo año y en ocasión de la Primera Conferencia Internacional del Trabajo, se adoptó una recomendación con miras a la instauración en todos los países miembros de un sistema que garantizará una inspección eficaz de las fábricas y talleres, así como de un servicio público encargado especialmente de proteger la salud de los obreros.

El otro avance en la misma dirección se dio en 1923, mediante una nueva recomendación internacional que constituyó el núcleo de los principios que informan los actuales sistemas de inspección de trabajo, y con lo cual se logra la adopción en 1947 del Convenio $N^{\circ} 81$ relativo a la Inspección en la Industria y el Comercio, que constituye el instrumento de referencia universal en materia de inspección de trabajo $^{21}$.

20 Estudio General sobre Inspección del Trabajo 2006. OIT. Párrafos 3 y 4

21 Estudio General sobre Inspección del Trabajo 2006. OIT. Párrafos 3 y 4

\section{A. Aspectos doctrinarios de la inspección de trabajo.}

\section{Delimitación conceptual:}

En su acepción general la palabra "inspección" entraña diversos significados tales como: examen, observación o reconocimiento de algo, vigilancia, revisión o cuidado. En este apartado estamos analizando la expresión, "como un núcleo o cuerpo que desenvuelve una actividad en alguna esfera y cual jurisdicción de los inspectores y organización de los mismos, surge la noción de inspección de trabajo como servicio oficial administrativo encargado de velar por el cabal cumplimiento y proponer la mejora de las leyes y reglamentaciones laborales, con la finalidad de prestaciones más seguras, higiénicas, estables y ajustadas al interés público general de la producción y del equilibrio social ${ }^{22}$.

A efecto de precisar de forma conceptual la institución jurídica objeto de nuestro estudio, es importante separar los conceptos "Inspección de Trabajo" de "Sistema de Inspección de Inspección de Trabajo", el primero, puede ser definido como: un instrumento primordial sobre el que los Estados reposan para garantizar la eficacia normativa. En cambio el segundo, es un conjunto de principios legales, normas, órganos, funcionarios y medios materiales que contribuyen al adecuado cumplimiento de las normas laborales, de prevención de riesgos laborales y de seguridad social $^{23}$.

En todo caso existe una relación de género a especie entre ambos conceptos, siendo más amplio el segundo en mención. El significado de ambas categorías constituye un servicio público, cuya finalidad es vigilar y garantizar que se cumplan las normas jurídicas relativas al trabajo que son de su competencia.

\section{Necesidad social de la inspección de trabajo:}

Un Estado de derecho siempre se caracterizará por hacer prevalecer el imperio de la ley y la institucionalidad. En el

22 Cabanellas de Torres, Guillermo. Compendio de Derecho Laboral. Tercera Edición Actualizada y Ampliada. Tomo II Editorial Heliastra. Buenos Aires 1992. Pág. 881

23 Olea, Manuel Alonso y otros. "Derecho del Trabajo". Décimo octava Edición Revisada. Civitas. Madrid. 2000 Pág. 1081. 
derecho del trabajo la intervención de un Estado con estas características es imprescindible, a efecto para lograr el equilibrio entre empleadores y trabajadores, pero también es importante hacer cumplir los mínimos normativos para que exista ese equilibrio, y como consecuencia la paz social en las empresas. Es entonces el Estado con su poder de imperio el que custodia que los derechos y garantías se apliquen de forma concreta y eficaz en la realidad.

Uno de los medios de que se vale el Estado para procurar la paz social, es la instauración de los sistemas de inspección de trabajo, los cuales no tienen como objeto suplir o sustituir los poderes judiciales, sino más bien complementar y sobre todo fortalecer los sistemas jurisdiccionales de justicia laboral $^{24}$ De ahí que muchos tratadistas denominen a este sistema como un régimen de policía laboral o como un derecho administrativo del trabajo.

Parafraseando a Cabanellas de Torres: no basta con dictar leyes que protejan al trabajador, se impone que se organice la institución encargada de comprobar ese cumplimiento. Agrega: "Sin inspectores, sin la potencial visita de los mismos, sin el "riesgo" de una denuncia para los transgresores, los empresarios no tardarían tal vez en recuperar su posi-

24 De Diego, Julián Arturo. "Manual de Derecho del Trabajo y de la Seguridad Social". $5^{a}$ Edición: Lexis Nexis. Abeledo- Perot. Buenos Aires. 2002 Pág. 598. ción avasalladora de los primeros tiempos de la revolución industrial.. $^{25,}$

Para Vásquez Vialard la inspección de trabajo tiene una doble función: a) La preventiva y educativa, a fin de facilitar el debido cumplimiento de las leyes laborales; y b) La sancionatoria o punitiva de las infracciones observadas ${ }^{26}$.

Nota importante: El presente artículo es parte de un estudio jurídico patrocinado por el proyecto Cumple y Gana para potenciar las capacidades de gestión del Ministerio de Trabajo y Previsión Social de El Salvador.-

25 Cabanellas de Torres, Guillermo. Compendio de Derecho Laboral. Tercera Edición Actualizada y Ampliada. Tomo II Editorial Heliastra. Buenos Aires 1992. Pág. 882

26 Vásquez Vialard, Antonio, "Derecho del Trabajo y de la Seguridad Social". Tomo II Octava Edición. Editorial Astrea. Buenos Aires. Pág. 284. 